\title{
Long-term follow-up on MURCS (Müllerian duct, renal, cervical somite dysplasia) association and a review of the literature
}

\author{
Sun Kim, MD', \\ Yeong Seok Lee, MD', \\ Dong Hyun Kim, MD, PhD', \\ Aram Yang, $\mathrm{MD}, \mathrm{PhD}^{1}$, \\ Tack Lee, MD, PhD², \\ Seun Deuk Hwang, MD, \\ Dae Gyu Kwon, MD ${ }^{4}$, \\ Ji Eun Lee, MD, PhD'
}

'Department of Pediatrics, Inha University Graduate school of Medicine, Inha University Hospital, Incheon, Korea ${ }^{2}$ Department of Urology, Inha University College of Medicine, Incheon, Korea

${ }^{3}$ Department of Internal Medicine, Inha University College of Medicine, Incheon, Korea

${ }^{4}$ Department of Orthopaedic Surgery, Inha University Hospital, Incheon, Korea

Received: 1 September, 2018

Revised: 1 April, 2019

Accepted: 12 April, 2019

Address for correspondence:

Ji Eun Lee, MD, PhD

Department of Pediatrics, Inha University Hospital, Inha University School of Medicine, 27 Inhang-ro, Jung-gu, Incheon 22332, Korea

Tel: +82-32-890-3617

Fax: +82-32-890-2844

E-mail: anicca@inha.ac.kr

https://orcid.org/0000-0002-73860015
Müllerian duct aplasia-renal aplasia-cervicothoracic somite dysplasia (MURCS) association is a unique development disorder with four common types of malformations that include uterine aplasia or hypoplasia, renal ectopy or agenesis, vertebral anomalies, and short stature. The majority of MURCS patients are diagnosed with primary amenorrhea from late-adolescence. However, a few cases with MURCS association are not well diagnosed during childhood and long-term outcomes are not well reported. We report a case of an 8-year-old girl with MURCS association who presented with recurrent urinary tract infections and multiple congenital malformations, and who was followed for 10 years until adulthood. MURCS association should be considered as one of the differential diagnoses when evaluating prepubertal females with vertebral and renal malformations.

Keywords: Mullerian aplasia, Müllerian duct aplasia-renal aplasia-cervicothoracic somite dysplasia association, Mayer-Rokitansky-Küster-Hauser anomaly, Child

\section{Introduction}

Mayer-Rokitansky-Küster-Hauser syndrome (MRKH; Online Mendelian Inheritance in Man (OMIN) \#277000) is characterized by developmental failure of the Müllerian duct and is often found in combination with urological and skeletal anomalies. ${ }^{1,2)}$ Müllerian duct aplasiarenal aplasia-cervicothoracic somite dysplasia (MURCS) association (OMIN \#601076), which could be classified as a subtype of MRKH, is a unique development disorder with four common types of malformations, including uterine aplasia or hypoplasia, renal ectopy or agenesis, vertebral anomalies and short stature (adult height less than $152 \mathrm{~cm}$ ). ${ }^{1,3)}$ MURCS association was first defined by Duncan et al. in $1979^{3)}$ as congenital supravaginal and uterus, renal and cervicothoracic abnormalities. Other organ deformities were subsequently reported, such as external ear anomalies, deafness, facial asymmetry, and cardiac defects. ${ }^{4)}$

In affected patients, the classical presentations of MUCRS, as demonstrated in cases with $\mathrm{MRKH}{ }^{5)}$ are primary amenorrhea with normally-developed secondary sexual characteristics and normal karyotype. Therefore, the majority of the MURCS patients have been diagnosed with primary amenorrhea since late-adolescence. To date, few cases of MURCS association have been diagnosed during childhood and long-term outcomes are not well reported. We report a case of an 8-year-old girl with MURCS association who presented with severe short stature, recurrent urinary tract infection, and multiple congenital malformations who was followed for 10 years until adulthood, and we present a review of the literature.

\section{Case report}

An 8-year-old girl with a history of renal anomaly was referred to our hospital for 
evaluation of other organ deformities. The patient had lived in an orphanage since birth. Family and prenatal histories were not confirmed. She had undergone open-heart surgery due to a ventricular septal defect at the age of 6 months at another hospital. The patient was frequently treated for recurrent urinary tract infections. At the age of 4 years, she underwent an operation due to a diagnosis of vesicoureteral reflux (VUR) and a single dysplastic kidney in the pelvis.

On admission, the vital signs were as follows: systolic and diastolic blood pressure 118 (95th percentile) and $65 \mathrm{mmHg}$ (75th-95th percentile); pulse rate 70 times/min.; respiratory rate 20 times $/ \mathrm{min}$.; body temperature $36.2^{\circ} \mathrm{C}$. Body weight was $13.3 \mathrm{~kg}$ (-5.42 standard deviation score [SDS]) and height was $91.2 \mathrm{~cm}$ (-7.91 SDS). Physical examination revealed facial asymmetry, a short neck, external ear aplasia on the right side (Fig. 1), and right thumb hypoplasia. She had normal female external genitalia and showed normal intellectual development. Initial blood examination results were as follows: hemoglobin, $10.7 \mathrm{~g} / \mathrm{dL}$; leukocyte, $8,020 / \mu \mathrm{L}$; platelet count, $355 \times 10^{3} / \mathrm{mm}$; serum total protein, $8.7 \mathrm{~g} / \mathrm{dL}$; serum albumin, $4.7 \mathrm{~g} / \mathrm{dL}$; total cholesterol, $246 \mathrm{mg} / \mathrm{dL}$; aspartate aminotransferase, $38 \mathrm{IU} / \mathrm{L}$; alanine aminotransferase, $21 \mathrm{IU} / \mathrm{L}$; serum sodium, $141 \mathrm{mEq} /$ L; potassium, $4.9 \mathrm{mEq} / \mathrm{L}$; chloride-, $109 \mathrm{mEq} / \mathrm{L}$. The blood urea nitrogen (BUN) and serum creatinine were $31.9 \mathrm{mg} / \mathrm{dL}$ and $1.40 \mathrm{mg} / \mathrm{dL}$, respectively, and the glomerular filtration rate (by calculated Schwartz formula) was $35.8 \mathrm{~mL} / \mathrm{min} / 1.73 \mathrm{~m}^{2}$. The urinalysis showed normal findings. The karyotype was normal female as 46, XX. The serum insulin-like growth factor 1 level was within the normal range as $186.0 \mathrm{ng} / \mathrm{mL}$ (normal range, 100-446 ng/mL).

A growth hormone $(\mathrm{GH})$ stimulation test was performed to evaluate her extremely short stature. In the levodopa provocative test, the GH levels showed an exaggerated increase from $3.98 \mathrm{ng} / \mathrm{dL}$ to $46.5 \mathrm{ng} / \mathrm{dL}$ compared to the GH deficiency. The spine X-ray showed a fusion of $\mathrm{C} 2-3$, and $\mathrm{C} 4-5$ vertebrae as well as a fusion of L1-2, and L3-4 vertebrae. The costal X-ray showed that the 1st and 2 nd ribs on both sides were fused. The $\mathrm{X}$-ray also showed scoliosis and sacrococcygeal agenesis (Fig. 2). Abdominal computed tomography revealed a single left dysplastic kidney, located in the pelvis, and uterine aplasia (Fig. 3 ). Evaluation of the auditory system revealed sensorineural hearing loss of the right ear as well as external ear malformation. Based on the co-occurrence of all deformities, the patient was diagnosed with MURCS association. She was estimated to have chronic kidney disease (CKD) stage $3 \mathrm{~b}$, and she underwent a suprapubic cystostomy with a Foley catheter insertion to

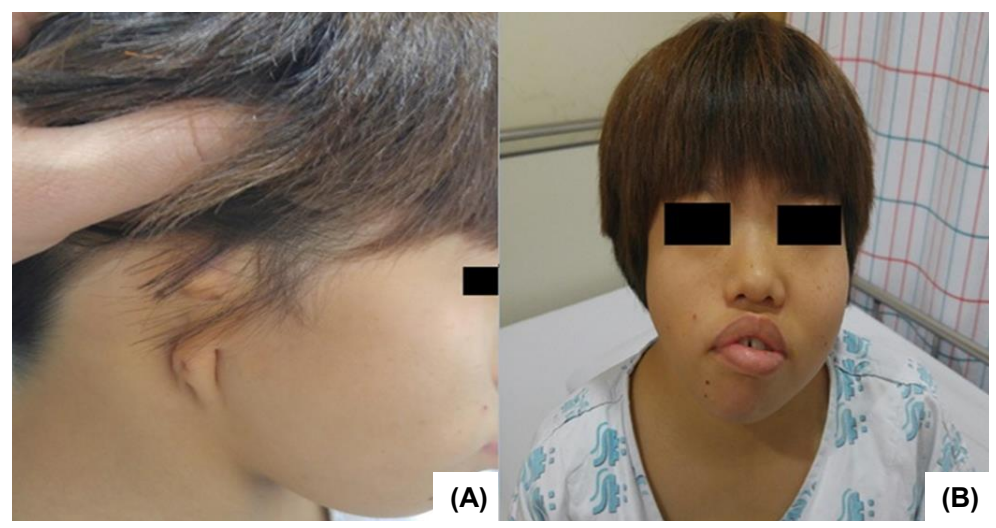

Fig. 1. Image showing external ear atresia (A), short neck and facial asymmetry (B).

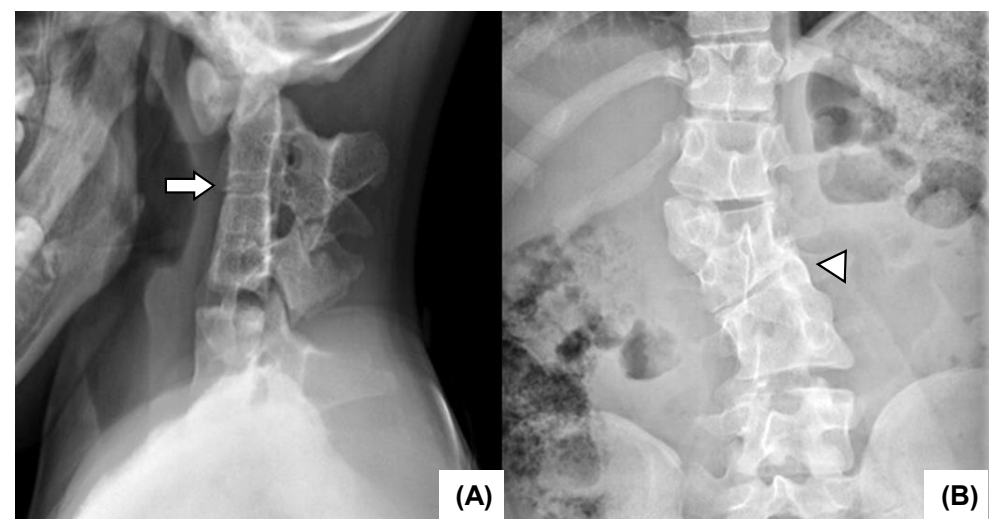

Fig. 2. X-ray C-spine showed a bony fusion on C2-3, C4 vertebrae (arrow) (A) and scoliosis of L-spine (arrowhead) (B). 


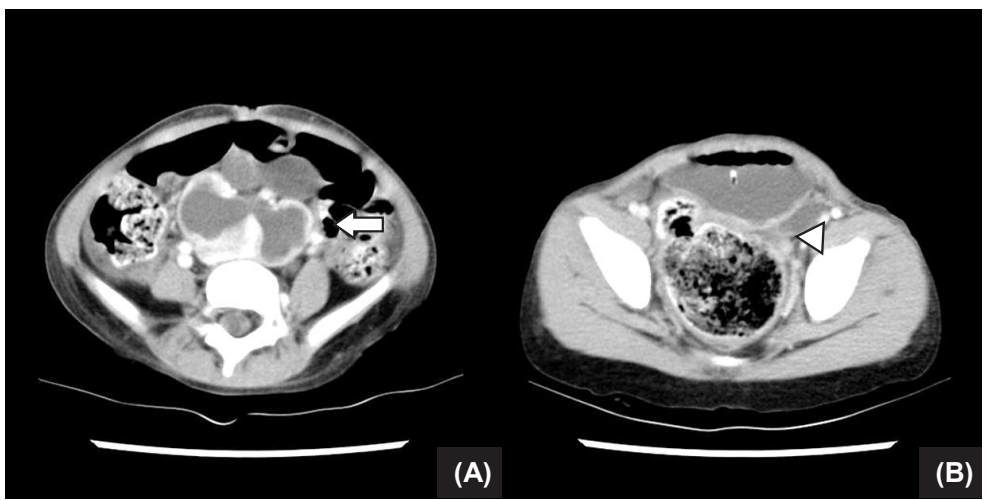

Fig. 3. Abdominal computed tomography showed a single dysplastic kidney (arrow) (A) and uterine aplasia (arrowhead) (B).

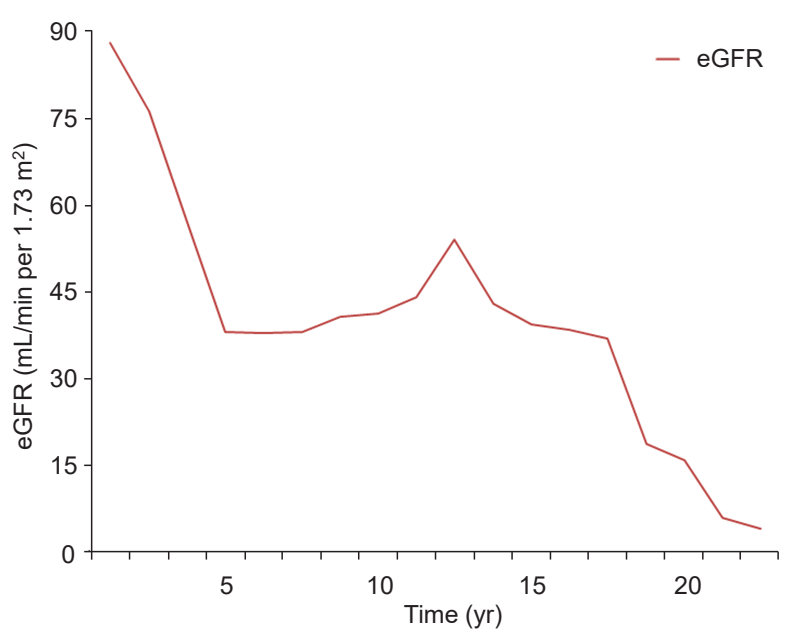

Fig. 4. Estimated glomerular filtration rate (eGFR) of our patient. It declines gradually during follow-up period.

maintain a residual renal function. The patient started dietary intervention and conservative management, including oral medications of sulfonate calcium, cholecalciferol, and sodium bicarbonate. She started wearing a hearing aid and received psychiatric counseling. At the age of 12, the patient's medical condition was maintained, and height was $107.9 \mathrm{~cm}$ (-6.04 SDS) and weight $17.5 \mathrm{~kg}$ (-5.47 SDS). On physical examination, she showed the beginnings of secondary sexual characteristics such as thelarche (Tanner stage B2). The serum BUN and creatinine were $34.0 \mathrm{mg} / \mathrm{dL}$ and $1.73 \mathrm{mg} / \mathrm{dL}$, respectively, and the glomerular filtration rate (Schwartz formula) was maintained as $34.3 \mathrm{~mL} / \mathrm{min} / 1.73 \mathrm{~m}^{2}$. At the age of 18 , her height was 132.6 $\mathrm{cm}$ (-5.78 SDS), her weight was $29.9 \mathrm{~kg}$ (-6.29 SDS), and blood pressure was 118 (50th-75th percentile) $/ 75 \mathrm{mmHg}$ (50th-75th percentile), and her pubertal development was complete, excluding menarche. Laboratory test results to evaluate her primary amenorrhea were as follows: LH was $16.0 \mathrm{mIU} / \mathrm{mL}$ (normal range, $0.5-7.6 \mathrm{mIU} / \mathrm{mL}$ ), FSH was $2.43 \mathrm{mIU} / \mathrm{mL}$ (normal range, $1.2-13.4 \mathrm{mIU} / \mathrm{mL}$ ), estradiol was $58.01 \mathrm{pg} / \mathrm{mL}$ (normal range, 54-242 pg/mL), dehydroepiandrosterone-sulfate

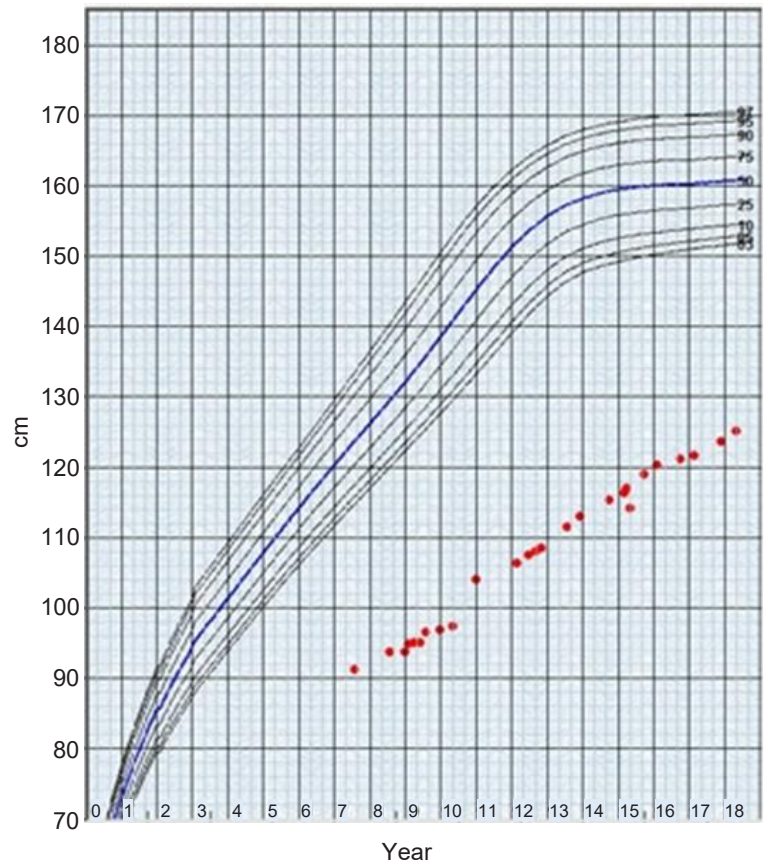

Fig. 5. Growth curve of our patient. It shows extreme short stature with significant catch-down growth during follow-up period.

was $80.3 \mu \mathrm{g} / \mathrm{dL}$ (normal range, $66-255 \mu \mathrm{g} / \mathrm{dL}$ ), and the antiMüllerian hormone was $3.43 \mathrm{ng} / \mathrm{mL}$ (normal range, 2.0-6.8 ng/ $\mathrm{mL}$ ). The renal functions had gradually declined; serum BUN and creatinine were $62.9 \mathrm{mg} / \mathrm{dL}$ and $5.05 \mathrm{mg} / \mathrm{dL}$, respectively, and the glomerular filtration rate (Schwartz formula) was 14.4 $\mathrm{mL} / \mathrm{min} / 1.73 \mathrm{~m}^{2}$. She was scheduled to undergo continuous ambulatory peritoneal dialysis due to CKD stage 5 (end-stage renal disease) (Fig. 4). Since the procedure, she has been on peritoneal dialysis and receives conservative treatment as a renal replacement therapy.

\section{Discussion}

MURCS association is a rare and unusual disorder with 
multi-organ malformations and has not yet been reported in Korea. According to Guerrier et al., ${ }^{4)}$ defects of the reproductive organs are found in most cases of MURCS, while renal anomalies, including unilateral renal agenesis or ectopic or horseshoe kidney are reported in only $50 \%$ of cases. In addition, cervicothoracic vertebral anomalies are found in only $20 \%$ of cases. Other minor organ deformities are occasionally detected at a low incidence. Our patient had the 4 major anomalies of MURCS association, uterine agenesis, an ectopic single kidney with VUR, multiple vertebral anomalies, and short stature (Fig. 5), and also had other minor clinical features of a congenital heart defect, other skeletal anomalies including facial asymmetry, a short neck, and external ear malformation with deafness. In addition, our patient showed an exaggerated GH response to the $\mathrm{GH}$ stimulation test. To our knowledge, there has not been data reported for a GH stimulation test in MURSC association, which makes it difficult to establish a causal relationship with the disease. In this case, the rarity and clinical significance of these syndromes are highlighted (Table 1) (6-9) $^{-9}$

MURCS association should be differentiated from various conditions such as Klippel-Feil syndrome, VACTERL association and Goldenhar syndrome due to similar accompanying anomalies. Genital deformities are rare in VATERL association, which is characterized by vertebral defects, renal anomalies, tracheoesophageal fistula, and anal atresia. ${ }^{10)}$ Klippel-Feil syndrome is typically related to facial asymmetry and vertebral anomalies, while it is rarely associated with reproductive involvement. Goldenhar syndrome can present with similar skeletal anomalies in the face, auricle, and vertebral spectrum, compared to MURCS, however urogenital deformities are rare.

The pathogenesis of the association between MURCS and urogenital deformities has not been elucidated. During development, at the end of the fourth week of fetal life, the blastemas of the cervicothoracic somite, arm buds, and pronephric buds are in close proximity. ${ }^{3)}$ At this time, MURCS association may develop because of a teratogenic effect, which would affect the relationship between these blastemas.

Although most cases are sporadic, some cases are reported to have a family history with autosomal dominant inheritance but incomplete penetrance. A recent genetic study on the disorder focused on various relevant genes, such as the WNT and HOX genes. The WNT genes, which encode the glycoprotein that controls the growth and differentiation of cells in the embryo stage, were expressed when female genitalia had formed in mouse experiments and mutated in cases of various Müllerian agenesis. ${ }^{11)}$ HOX genes are associated with the development of the Müllerian duct and also the kidneys and the skeleton; thus, a defect in these genes is likely to be related to MURCS association. ${ }^{12)}$ However, to date, research has not yet defined the role of these genes in the pathogenesis of MURCS. ${ }^{413)}$

This report demonstrates the importance of evaluating kidney or uterine anomalies via abdominal ultrasonography in patients with extremely short stature and with multiple skeletal anomalies. Management and prognosis of MURCS case varies depending on the extent of organ involvement, especially the kidneys. In this case, the severe urological anomalies were the critical prognostic factor. ${ }^{14)}$ Therefore, to ensure the quality of life in MURCS patients, it is important to delay or prevent the progression of ESRD. In conclusion, MURCS association should be considered as a differential diagnosis when evaluating prepubertal female patients with vertebral and renal malformations.

Table 1. Summary of case reports of MURCS and associated defects

\begin{tabular}{|c|c|c|c|c|c|}
\hline Variable & Braun-Quentin et al.' & Gilliam et al. & Kumar et al. & Al Kaissi et al. & Present case \\
\hline Country & Germany & USA & India & Tunisia & Korea \\
\hline Sex & Female & Female & Female & Female & Female \\
\hline Age & 25 & 15 & 28 & 17 & 8 \\
\hline \multicolumn{6}{|l|}{ Major factor } \\
\hline Uterus aplasia & + & + & + & + & + \\
\hline Kidney malformation & + & None & + & None & + \\
\hline Short neck & None & N/A & + & + & + \\
\hline Short stature & $\begin{array}{c}152 \mathrm{~cm} \\
\text { (3rd percentile) }\end{array}$ & $\begin{array}{c}62 \mathrm{~cm} \\
(<3 \mathrm{rd} \text { percentile })\end{array}$ & $\begin{array}{c}146 \mathrm{~cm} \\
(<3 \mathrm{rd} \text { percentile })\end{array}$ & $\begin{array}{c}141 \mathrm{~cm} \\
(<3 r d \text { percentile })\end{array}$ & $\begin{array}{c}91.2 \mathrm{~cm} \\
(<3 \text { rd percentile) }\end{array}$ \\
\hline Vertebrae defect & + & N/A & + & + & + \\
\hline \multicolumn{6}{|l|}{ Minor factor } \\
\hline Vaginal aplasia & + & + & None & + & + \\
\hline Scoliosis & $\mathrm{N} / \mathrm{A}$ & $\mathrm{N} / \mathrm{A}$ & + & + & + \\
\hline Rib defect & + & $\mathrm{N} / \mathrm{A}$ & + & $\mathrm{N} / \mathrm{A}$ & + \\
\hline Thumb hypoplasia & $\mathrm{N} / \mathrm{A}$ & $\mathrm{N} / \mathrm{A}$ & $\mathrm{N} / \mathrm{A}$ & $\mathrm{N} / \mathrm{A}$ & + \\
\hline Deafness & $\mathrm{N} / \mathrm{A}$ & $\mathrm{N} / \mathrm{A}$ & $\mathrm{N} / \mathrm{A}$ & $\mathrm{N} / \mathrm{A}$ & + \\
\hline External ear malformation & None & None & None & None & + \\
\hline Facial asymmetry & + & None & + & None & + \\
\hline Cardiac defect & None & + & $\mathrm{N} / \mathrm{A}$ & $\mathrm{N} / \mathrm{A}$ & + \\
\hline
\end{tabular}

MURCS, Müllerian duct aplasia-renal aplasia-cervicothoracic somite dysplasia; N/A, not available.

Major and Minor factors were defined by Duncan et al. ${ }^{3)}$ 


\section{Ethical statement}

This study was approved by the Institutional Review Boards (approval number: 2018-04-027) of the Inha University Hospital. Written informed consent was obtained from both the patient and the guardian for publication of this report.

\section{Conflict of interest}

No potential conflict of interest relevant to this article was reported.

\section{Acknowledgments}

This paper was presented at the 67 th Conference of the Korean Pediatric Society in 2017.

\section{References}

1. Kang Ben, Park SH, Kim DH, Lee BI, Kim MY, Lee JE. Mayer-Rokitansky-Kuster-Hauser (MRKH) syndrome in a child with idiopathic precocious puberty. Ann Pediatr Endocrinol Metab 2012;17:126-9

2. Mahajan P, Kher A, Khungar A, Bhat M, Sanklecha M, Bharucha BA. MURCS association--a review of 7 cases. J Postgrad Med 1992;38:109-11.

3. Duncan PA, Shapiro LR, Stangel JJ, Klein RM, Addonizio JC. The MURCS association: Müllerian duct aplasia, renal aplasia, and cervicothoracic somite dysplasia. J Pediatr 1979;95:399-402.

4. Guerrier D, Mouchel T, Pasquier L, Pellerin I. The MayerRokitansky-Küster-Hauser syndrome (congenital absence of uterus and vagina)--phenotypic manifestations and genetic approaches. J Negat Results Biomed 2006;5:1.

5. Park JY, Kim SY, Kim JN, Yang SJ, Park JR, Kwan BS, et al. A case of colon cancer in Mayer-Rokitansky-Küster-Hauser
(MRKH) syndrome with gonadal agenesis. J Korean Endocri Soc 2006;21:414-8.

6. Braun-Quentin C, Billes C, Böwing B, Kotzot D. MURCS association: case report and review. J Med Genet 1996;33:618-20.

7. Gilliam ML, Shulman LP. Tetralogy of Fallot, imperforate anus, and Müllerian, renal, and cervical spine (MURCS) anomalies in a 15-year-old girl. J Pediatr Adolesc Gynecol 2002;15:231-3.

8. Kumar S, Sharma S. MURCS (Müllerian duct aplasiarenal agenesis-cervicothoracic somite dysplasia): a rare cause of primary amenorrhoea. Oxf Med Case Reports 2016;2016:73-5.

9. Al Kaissi A, Ben Chehida F, Ben Ghachem M, Grill F, Klaushofer K. Occipitoatlantoaxial junction malformation and early onset senile ankylosing vertebral hyperostosis in a girl with MURCS association. Am J Med Genet A 2009;149A:470-4.

10. Källén K, Mastroiacovo P, Castilla EE, Robert E, Källén B. VATER non-random association of congenital malformations: study based on data from four malformation registers. Am J Med Genet 2001;101:26-32.

11. Miller C, Sassoon DA. Wnt-7a maintains appropriate uterine patterning during the development of the mouse female reproductive tract. Development 1998;125:3201-11.

12. Gendron RL, Paradis H, Hsieh-Li HM, Lee DW, Potter SS, Markoff E. Abnormal uterine stromal and glandular function associated with maternal reproductive defects in Hoxa-11 null mice. Biol Reprod 1997;56:1097-105.

13. Burel A, Mouchel T, Odent S, Tiker F, Knebelmann B, Pellerin I, et al. Role of HOXA7 to HOXA13 and PBX1 genes in various forms of MRKH syndrome (congenital absence of uterus and vagina). J Negat Results Biomed 2006;5:4.

14. Edmonds DK. Congenital malformations of the genital tract and their management. Best Pract Res Clin Obstet Gynaecol 2003;17:19-40. 